\title{
Um sentido para as aparências: cenas e máscaras do/ no cotidiano formativo
}

\author{
Clívio Pimentel Júnior \\ Maria Inez da Silva de Souza Carvalho \\ Universidade Federal da Bahia
}

\section{Resumo}

artigo, construído por meio de uma descrição interpretativa dos cotidianos escolares e universitários vivenciados por licenciandos em Biologia, tem como objetivo analisar as aparências do estar-junto no grupo através da formação científica universitária. O método, construído com base nas teorizações de Carvalho (2001), Erickson (1985) e Maffesoli (1996), culminou em episódios interpretativos como modo de apreensão dos fenômenos cotidianos, aliados a discussões teóricas. Revelam-se compreensões construídas em referência aos valores e crenças compartilhadas pelo grupo que, ao lado da possibilidade de identificá-lo esteticamente, permite a compreensão dos totens em torno dos quais o grupo gira, formados nos espaços formativos vividos.

180 Palavras-chave: Currículo. Estética. Pós-modernidade.

\section{A meaning for appearances: scenes and masks in formative daily life}

\section{Abstract}

The article, built through a interpretative description of schools and universities everyday life experienced by undergraduates in Biology, aims to analyze the appearances of being-together in group through a study of scientific training college. The method, constructed from the theories of Carvalho (2001), Erickson (1985) and Maffesoli (1996), culminated in interpretive episodes, as a way of understanding the everyday phenomena, combined with theoretical discussions. Reveal understandings built up in reference to the values and beliefs shared by a group, beside the possibility to identify it aesthetically, allows understanding the totems around which the group responds, formed in experienced formative spaces.

Keywords: Curriculum. Aesthetics. Post-Modernity. 


\section{Un sentido de las apariencias: las escenas y los tonos de formación en diario}

\section{Resumen}

El artículo ha sido construido a través de una descripción interpretativa del cotidiano de escolares y universitarios vivenciados por estudiantes licenciados en Biología, analiza las apariencias de estar-junto en grupo a través de la formación científica. El método, construido a partir de las teorías de Carvalho (2001), Erickson (1 985) y Maffesoli (1996), culminó con episodios interpretativos de fenómenos cotidianos, junto con discusiones teóricas. Se revelan entendimientos construidos en referencia a los valores y creencias compartidas por el grupo que, además de la posibilidad de identificarlo estéticamente, permite entender los tótems en torno al cual gira el grupo, formados en espacios formativos vividos.

Descriptores: Currículum. Estética. Postmodernismo.

\section{Introdução}

Estamos vivenciando um período que requer grandes reajustamentos. Um deles é aprender mais uma vez a sustentar crenças, nossas próprias crenças. A tarefa é formidável, pois por séculos fomos ensinados a crer apenas no resíduo daquilo que não possa ser assaltado por dúvidas. Não mais existe tal resíduo hoje em dia, daí a necessidade de readquirirmos mais uma vez e sistematicamente, a capacidade de acreditar com os olhos abertos (POLANYI, 2003).

trabalho em pauta apresenta as constatações construídas numa pesquisa de mestrado defendida no Programa de Pós-graduação em Educação da Faculdade de Educação, Universidade Federal da Bahia (FACED/UFBA). Os posicionamentos defendidos aqui derivam, em grande parte, do que vimos, semanalmente, discutindo em nossas reuniões do grupo de pesquisa Formação em Exercício de Professores (FEP), alocado na linha de pesquisa Currículo e (In) formação dessa mesma Faculdade. Estudos que perseguem, sobretudo, concepções e noções menos finalistas e totalizantes quando o assunto é currículo e processo formativo. 
Notadamente, diríamos noções e concepções desviacionistas em relação à ordem discursiva em pronunciamento. Para os propósitos desta introdução, gostaríamos de anunciar algumas posturas adotadas neste trabalho, mesmo quando podem ser consideradas, por alguns, como imposturas e/ou marginais. Em consonância com os discursos aliados ao que se denominou de Pós-Modernidade, as noções aqui apresentadas distanciam-se de pretensões fundamentalistas, de textos certos, que comumente fornecem explicações dotadas de consequencialidade e inexorabilidade no que tange aos rumos a serem tomados, tal como uma nau que, ao adentrar no mar, está mais preocupada com as entradas e saídas, os portos, as extremidades. Interessa-nos mais explicitar marcas de um caminho sempre em (re)construção de campos de possibilidades geohistoricamente gestadas e finitas: caminhos possiveis de uma nau aparentemente sem rumo, o navegar, os trajetos.

A noção de Pós-Modernidade aqui apresentada está em consonância com a caracterização feita por Peters (2000) no que tange à compreensão desse movimento não como uma forma de estar/se relacionar no/com o mundo necessariamente melhor, mas diferente. Trata-se de um movimento que não apela para "metanarrativas explicativas", mas sugere objetivos, textos e compreen182 sões mais modestas a partir do entendimento de que o olhar pontual, quando imerso num espaço-tempo circundante complexo, multifacetado, polissêmico, não comporta a adoção de viseiras explicativas simplificadoras, mas de perspectivas oculares distintas. Importante ressaltar que até mesmo o significado do termo Pós-Modernidade, levando em consideração as perspectivações, torna-se flutuante e potencialmente heurístico:

[...] eles [os significados] têm mudado historicamente, como resultado da atividade teórica, criando-se, assim, novos significados e interpretações. Nesse sentido, podemos dizer que não existe qualquer fechamento em torno de uma definição única. Seus significados são, sempre, questionáveis, estando abertos à interpretação, sobretudo, na medida em que as pessoas que estudam esses movimentos utilizam esses termos de forma a torná-los teoricamente produtivos. De fato, poder-se-ia argumentar que quando essas definiç̃̃es e significados tornam-se fixos é porque o discurso teórico esgotou-se (PETERS, 2000, p. 16).

Já de acordo com Vattimo (2007), pensar a Pós-modernidade a partir da relação que liga as reflexões nietzschianas e heideggerianas do eterno 
retorno e do ultrapassamento da metafísica, respectivamente, é distanciar-se da kulturkritik do início do século XX:

Eles [Nietzsche e Heidegger] se acham, assim, por um lado, na condição de terem de distanciar-se criticamente do pensamento ocidental enquanto pensamento do fundamento; de outro, porém, não podem criticar esse pensamento em nome de uma outra fundação, mais verdadeira. É nisso que, a justo título, podem ser considerados os filósofos da pós-modernidade. $\bigcirc$ pós de pós-moderno indica, com efeito, uma despedida da modernidade, que, na medida em que quer fugir das suas lógicas de desenvolvimento, ou seja, sobretudo da ideia da 'superação' crítica em direção a uma nova fundação, busca precisamente o que Nietzsche e Heidegger procuraram em sua peculiar relação 'crítica' com o pensamento ocidental (VATTIMO, 2007, p. 6-7).

Como parte dos desdobramentos das reflexões nietzschianas e heideggerianas em relação ao questionamento da busca de fundamentos e valores supremos na história que, invariavelmente, perfaz uma trajetória superacionista, Vattimo convida-nos a experienciar o fim da história: um convite a profanar as histórias unitárias, as histórias dos vencedores - comumente seus protagonistas -, enfim, questionar as histórias assépticas que põem em funcionamento a teleologia e o finalismo em favor da perpetuação da lógica progressista, lógica essa fortemente legitimada através das fortes histórias modernas:

A pura e simples consciência - ou pretensão - de representar uma novidade na história, uma figura nova e diferente na fenomenologia do espírito, colocaria de fato o pós-moderno na linha da modernidade, em que domina a categoria de novidade e de superação. No entanto, as coisas mudam se, como parece deva-se reconhecer, o pós-moderno se caracterizar não apenas como novidade com relação ao moderno, mas também como dissolução da categoria do novo, como experiência de "fim da história", mais do que como apresentação de uma etapa diferente, mais evoluída ou mais retrógrada, não importa, da própria história IVATTIMO, 2007, p. 91.

Dissolução, em Vattimo, significa, antes de tudo, ruptura da unidade, e não fim puro e simples da história. Em outras palavras, a história universal torna-se impossível: a história atravessada pela busca de causas últimas e unificações totalitárias que comumente são dissolvidas, assim como os personagens criados 
para seus heróis. É a partir dessas pequenas e fracas categorias que conferimos legitimidade a uma história interpretativa que contamos neste trabalho, inventada e gestada com base em elucubrações implicadas:

A tarefa do pensamento não é mais, como sempre a modernidade pensou, remontar ao fundamento e, por essa via, encontrar o novum-ser-valor, que em seu desenrolar sempre posterior confere sentido à história: basta pensar como os renascimentos, na arte e na cultura ocidental, sempre foram inspirados por retomadas - da origem, do 'clássico', etc. 'Com o pleno conhecimento da origem aumenta a insignificância da origem.' Esse texto de Aurora resume ao menos em parte o que foi o destino do fundamento, da verdade, do grund, na análise química de Humano, demasiado humano. Não apenas a ideia do fundamento se dissolve 'logicamente', do ponto de vista de suas pretensões a valer como norma para o pensamento verdadeiro, mas também se revela, por assim dizer, vazia do ponto de vista do conteúdo: a insignificância da origem, quando se torna conhecida, aumenta e, por conseguinte, 'a realidade mais próxima, aquilo que está em torno e dentro de nós, começa pouco a pouco a mostrar cores e belezas e enigmas e riquezas de significado, coisas essas com que a humanidade antiga sequer sonhava' (VATIMO, 2007, p. 175).

Em Maffesoli (1996), o pós-moderno, fugindo ao que considera a violência moderna do trabalho exaustivo de definição do mundo, é visto como a junção do arcaico com o tecnológico. Arcaico na medida em que vislumbra valores outros na formação do corpo social contemporâneo: o prazer do estar-junto através do compartilhamento estético dos totens em torno dos quais as multidões se agrupam e não apenas as grandes categorias tributárias das atividades taxonômicas da modernidade:

O que dizer, senão que, num processo de massificação constante, operam-se condensações, organizam-se tribos mais ou menos efêmeras que comungam valores minúsculos e que, em um balé sem fim, entrechocam-se, atraem-se, repelem-se numa constelação de contornos difusos e perfeitamente fluidos. É essa a característica das sociedades pós-modernas (MAFFESOLI, 1996, p. 32).

Nesse sentido, operam-se atrações e repulsões no corpo social que, talvez, só poderá ser considerado como corpo no que este tem de orgânico e não máquina no que esta tem de mecânica, na medida em que aceita e coloca 
em contato o diferente e o contraditório no que estas qualidades têm de singular e complexo, respectivamente. A ideia de uma tribo, e consequentemente, dos valores de interesse - no sentido de inter esse - que a mantém coesa e viva, ter que se dobrar frente a valores compartilhados por outras tribos é posta de lado: a superioridade de valores que culmina em hierarquizações moralistas desmancha-se.

Adotando tais posturas e perspectivas no processo de narrar uma história sobre a formação científica através da análise do atual estado de formação de professores de biologia, pretendemos, apenas, ampliar o debate sobre a legitimidade dessas histórias fracas e deixar ver o modo como tais perspectivas deram forma às constatações que construímos no campo do currículo e da formação desses professores. Colocamos em suspensão o mundo dicotômico, os fardos insustentáveis, as ambições totalizantes nas narrativas e entregamo-nos à saborosa embriaguez labiríntica das (in)certezas das histórias fracas:

Nessa situação, deve-se falar, na minha opinião, de uma 'ontologia fraca' como única possibilidade de sair da metafísica - pelo caminho de aceitação-convalescença-distorção que não tem mais nada de ultrapassamento crítico característico da modernidade. Pode ser que nisso resida, para o pensamento pós-moderno, a chance de um novo, fracamente novo, começo (VATTIMO, 2007, p. 190, grifo meu).

Desnecessário falar que, em se tratando das posturas aqui adotadas, não há nenhuma justificativa de cunho depreciativo de outros movimentos: trata-se de entendê-los como respostas dadas no seu espaço/tempo, fornecendo soluções aceitáveis na comunidade científica e, por isso, legítimas; evitemos, também, o anacronismo².

\section{Questões de método e técnicas de pesquisa}

Aliado às teorizações de Vattimo (2007), foi de fundamental importância o estudo das teorizações sociofenomenológicas de Maffesoli (1996, 2005, 2006), fazendo pensar sobre a forma formante e a dimensão estética do cotidiano a partir da noção de ambiência: "[...] nada escapa à ambiência de uma época, nem mesmo os que crêem ser completamente independentes" (MAFFESOLl, 2005, p. 105). Nesse sentido, intentamos criar um quadro 
interpretativo, descrever um ambiente, o ambiente curricular no qual os licenciandos ingressam no percurso formativo, tendo a dimensão estética da ambiência como elemento norteador daquilo que era vivenciado em campo:

É feito de uma multiplicidade de pequenas coisas e, claro, de estruturas macroscópicas. A conjunção e a reversibilidade destas determinam a maneira de viver de cada um e cadenciam a respiração social. Daí a necessidade, para compreender determinado espaço civilizacional, de questionar sobre a atmosfera que o banha e permite-the ser o que é (MAFFESOLI, 2005, p. 106).

Um termo que pode ajudar a reforçar a compreensão da noção de ambiência é o de espírito do tempo, Zeitgeist, que designa a atmosfera no que ela tem de objetivo e subjetivo, rompendo com as dicotomias tributárias da modernidade. Nesse sentido, levando em consideração essas duas dimensões do vivido, é possível perceber uma ênfase tanto no aspecto global quanto local sobre os diversos elementos do corpo social e, por outro lado, a impossibilidade de privilegiar qualquer um desses elementos, o que não quer dizer que a hierarquia entre eles deixa de existir, apenas frisa a imprescindibilidade de todos na rede de experiências que nos formam. Portanto, a força da ambiência englobante determina profundamente as atitudes individuais, os modos de vida, as maneiras de pensar e as diversas inter-relações sociais, econômicas, políticas, ideológicas, religiosas, constituindo a vida em sociedade. Existe uma contaminação do corpo social através da respiração dessa atmosfera, do metabolismo de seus ares no dia a dia, engendrando notadamente um ethos. A metáfora da dança, que coloca em discussão também a noção de ritmo, é ilustrativa e auxilia na compreensão:

A comparação com uma figura de dança é esclarecedora aqui. Vê-se bem como, em sequências sucessivas, o dançarino cria seu equilíbrio, sempre provisório, mas que o situa no conjunto da dança, onde outros fazem a mesma coisa, compondo assim o quadro que se pode admirar. Nesse sentido, o dever tido em relação a si mesmo e ao próprio corpo, sendo harmonioso, serve ao corpo social na sua totalidade. [...] Assim, levando em consideração a sua etimologia, vê-se que o ritmo, mesmo contendo e pressionando a força inerente ao querer-viver individual, permite, de uma parte, uma espécie de autocriação equilibrada e, de outra parte, uma harmonia coletiva (MAFFESOLI, 2005, p. 137). 
A afiliação a essas teorizações orientou todo o trabalho de descrição feito em campo, a partir da identificação de como a força desses ares respirados ao longo da graduação determinavam as aparências do que os participantes da pesquisa viviam nas mais diversas situações anódinas do cotidiano, principalmente, mas não exclusivamente, em sala de aula. Nesse sentido, foi possível perseguir um dos enigmas construídos neste trabalho: o modo como se caracterizam as aparências do estado atual da formação científica, analisadas através da formação de professores em Ciências Biológicas, e suas ressonâncias no currículo escolar. Está em foco, neste trabalho, sobretudo, a epifanização de como os licenciandos dão forma às suas práticas de ensino com base no que é vivido ao longo da formação. Ou seja, pensar a organicidade que é levar em conta a força da ambiência como forjadora de uma Gestalt, um modo de modelar, dar forma e sentido às invenções cotidianas:

A forma é apenas uma tipificação elaborada a partir de dados observáveis, feitos à base de descrições sem que se trate de suspeitar, criticar o que é observado ou descrito. Isso força uma conversão do olhar: apreciar cada coisa a partir da sua própria lógica, de sua coerência subterrânea, e não a partir de um julgamento exterior que dita o que ela deve ser. Pode, portanto, haver uma lógica interna nessa situação que parece perfeitamente ilógica, pode-se encontrar uma no jogo da aparência, ou nesse ato perfeitamente frívolo. Ela pode variar na sua intenção ou aplicação; em compensação ela não varia na sua função agregativa. [...] A lógica interna de um conjunto particular deixa-se ver na multiplicidade de suas aparências. Resta, certamente, compreender como se faz a articulação de suas diversas aparências, como, para retomar uma posição weberiana, elabora-se a constelação: o que é que faz com que o jogo das formas se ordene? [...] A forma justifica, ao mesmo tempo, o geral e o particular, o 'universal concreto'. $\bigcirc$ universal, no caso, sendo o ambiente geral no qual nos banhamos, enquanto massa, o particular, ou o concreto, sendo a maneira pela qual um grupo vai se aninhar nesse ambiente geral, a maneira pela qual ele vai se apropriar de um valor geral ou de um conjunto de valores (MAFFESOLI, 1996, p. 143-146, grifo dos autores).

No que diz respeito às aparências, estas são entendidas como legítimas em si e dotadas de uma razão interna, e não como algo a ser desmascarado pelo pesquisador iluminado que desvenda a essência última e etérea das coisas do mundo. Essa conversão do olhar e o retorno às aparências, de notável 
inspiração nietzschiana, são defendidas também, por Gleiser (2010), quando, por meio de uma exploração existencial da história da física, constata o quanto a vontade de verdade última e de uma teoria final na ciência, ideologicamente construída desde os pré-socráticos por meio do que denomina "o delírio iônico" e, 25 séculos mais tarde, ainda presente na própria comunidade científica, pôs a própria comunidade em eterna suspeita em relação aos seus achados:

Será que precisamos acreditar numa verdade final para explorarmos os segredos mais profundos da natureza? Será que o universo precisa ser 'belo' para ser digno de estudo? Por que a insistência em relacionar a unidade de todas as coisas com a beleza? Será que não está na hora de celebrarmos um tipo diferente de beleza, inspirado nas imperfeições da Natureza em vez de suas supostas perfeições? Citando Wilczek: 'a fé na possibilidade de unificação nos remete a um estado em que nos recusamos a aceitar o que vemos... certamente, as aparências - ou melhor, nossa interpretação delas - devem estar nos enganando' (GLEISER, 2010, p. 184-185, grifo dos autores).

Assim, aceitando a ciência como uma exploração do mundo tal como ele é, e não como gostaríamos que fosse, constatamos: diversas são as máscaras, as estrelas, as aparências que compõem o lastro de referências das pessoas em seu relacionamento com o mundo, legítimas e dotadas de sentido. Referências estas, pensadas, mobilizadas e praticadas porque vividas num determinado espaço/tempo. Há viscosidade no ar! Viscosidade que confere função agregativa, forma corpo social a partir dos valores de inter-esse que são compartilhados por um grupo. Em paralelo ao aprofundamento nas questões de método em consonância com a perspectiva fenomenológica, a técnica de observação participante interpretativa proposta por Frederick Erickson (1985) mostrou-se teoricamente compatível aos propósitos do trabalho. Na vertente defendida por ele, as observações participantes e as pesquisas interpretativas estudam os sentidos atribuídos pelas pessoas aos fatos que acontecem cotidianamente tanto numa escala face-to-face (ERICKSON, 1985) quanto numa macroescala, ou seja, os eventos que ocorrem no entorno do contexto imediato das ações observadas. Assim, a observação participante interpretativa trabalha numa tentativa de apreender o como esses ares globais formam, em alguma medida, os sentidos expressos nas interações locais através das pessoas, que incorporam de maneira intensa e vivem esses sentidos, também, de acordo com suas singularidades. 
Seguindo essas orientações teórico-metodológicas, consideramos que o lócus mais apropriado, através do qual se pensaria a formação científica de professores e suas ressonâncias no currículo escolar, seria o próprio percurso formativo do primeiro autor do artigo - o curso de Licenciatura em Ciências Biológicas da Universidade Federal da Bahia (UFBA) -, sobretudo, no momento final do curso - o do estágio supervisionado da turma 2011.1 -, o qual possibilitou (re)viver tanto a formação no contexto universitário quanto no contexto inicial da prática de ensino e refletir mais atentamente sobre ele, uma escolha implicada ${ }^{3}$.

As observações ocorreram em dois campos principais: as aulas da disciplina Metodologia e Prática do Ensino de Biologia II, ministradas na Faculdade de Educação da Universidade Federal da Bahia - FACED/UFBA, bem como em uma das escolas onde os estudantes realizaram o estágio supervisionado, - Instituto Federal de Educação, Ciência e Tecnologia da Bahia (IFBA). Na Faculdade de Educação, as aulas foram acompanhadas durante todo o semestre de 2011.1 enquanto no IFBA, as aulas foram acompanhadas durante um bimestre de estágio supervisionado, também no período de 2011 . 1, por meio de observações diretas das aulas de um dos licenciandos do curso. Os registros desses momentos foram realizados em diário de campo, prática investigativa comum ao método etnográfico que, neste trabalho, foi efetivado com base nas formulações de Pimentel (2009) ${ }^{4}$. A escolha por trabalhar numa escala focada nos acontecimentos cotidianos - escolar e universitário - fundamenta-se por entendê-los como instituintes das práticas curriculares cuja dimensão criativa está para além do que é defendido no contexto dos textos "oficiais" e, ao mesmo tempo, incorpora-o numa linguagem referencialmente hibridizada. (ALVES, 2003; LOPES, 2005). Não se trata de uma simples rejeição do instituído, apenas a opção por uma aproximação dos fenômenos cotidianos em consonância com os referenciais trabalhados.

Com base na inter-relação entre as teorizações de Erickson (1985) no que diz respeito à coleta dos "dados" no campo empírico e à análise interpretativa deles bem como as de Maffesoli (1996, 2005, 2006) e Vattimo (2007), apresentamos os dados em forma de episódios que chamamos de Cenas e Máscaras do/no Cotidiano, tecidos nos cotidianos investigados. Os episódios foram criados tomando como referência as situações que provocavam atrações e repulsões, formação de núcleos fusionais entre os integrantes do grupo quando da emergência de situações vivenciadas e debatidas pelo grupo nos momentos 
iniciais de prática de ensino. $\bigcirc$ objetivo esteve sempre pautado na compreensão dos processos subjacentes que permitiam tais momentos de tribalizações a partir do que vinha sendo experimentado em comum, as aparências do estar-junto.

\section{Constatações acerca de um ambiente formativo}

As constatações construídas neste artigo fazem referência aos episódios interpretativos que nasceram com o que foi coletivamente experienciado ao longo do período de observação no campo empírico. Nesse sentido, para efeito de composição deste artigo, selecionamos um dentre os oito episódios interpretativos $^{5}$ que compuseram o texto final da pesquisa e, a seguir, apresentam-se algumas constatações em referência ao mesmo e aos cotidianos vivenciados durante a investigação.

\section{Cenas e Máscaras do/no Cotidiano Episódio 1 | A aplicação do conhecimento}

190 Diário de campo, Faculdade de Educação, Salvador, 29/03/2011

Curiosidade era a palavra de ordem no momento de apresentação da proposta da pesquisa de mestrado aos licenciandos do curso de Ciências Biológicas. Era preciso saber se os estudantes aceitariam o convite para participar da pesquisa na condição de pessoas pesquisadas, registrando suas falas, seus medos, suas angústias, seus conflitos, enfim, os valores em torno dos quais o grupo se unia, abrindo a possibilidade de identificá-lo nesse momento inicial de inserção no contexto da prática de ensino. Por minha parte, um frio na barriga que me fez tremer por alguns minutos e, por parte deles, receio e ansiedade em saber o que seria a tal pesquisa, como apareceriam nela.

Nesse momento, fico pensando no porquê de tanto receio em relação a ser pesquisado e me questiono se tal receio pode ser marcas de tradições de pesquisas que, comumente, tomam as falas dos participantes e tece-lhes críticas severas em relação às suas filiações político-epistemológicas, pouco elucidadas durante o percurso formativo e tão bem questionadas. Será que foram alunos desses questionadores durante o curso? Sem muito me alongar nessa pergunta e me prometendo refletir sobre ela depois, encaixo o pen drive no computador e 
inicio a apresentação. Ao terminá-la, logo fui abordado por Estudante 1, com a primeira colocação que me pôs a pensar:

Clívio, reconheço a importância da sua pesquisa, estou pegando EPC ${ }^{6}$ e lá discutimos bastante as questões ligadas a filosofia da ciência e ensino. Confesso que tive medo de pegar por causa da monografia, mas hoje to gostando muita das discussões. Apesar disso, vejo que não temos tempo na escola para discutir essas questões com os alunos, tenho certeza que se eu quiser conversar com eles sobre isso na aula, a professora da escola, que também foi minha professora, vai cortar na hora, vai mandar eu adiantar o conteúdo a ser dado pra não prejudicar o andamento do planejamento do ano (ESTUDANTE 1, 201 1).

De início, todas as pessoas concordaram com estudante 1: não dá pra aplicar esse conteúdo com os alunos. Além da impossibilidade de aplicação pela própria complexidade do assunto para aquele nível de ensino, vai atrasar toda a programação da escola e de biologia, que precisa ser terminada até o final do ano e será fortemente cobrada pelos professores supervisores do estágio. Por impulso e sem parar pra pensar o que aquela situação expressava, me apressei para desfazer aquele mal-entendido: a proposta de fato não era levar aos estudantes do ensino médio os temas que ora tinha apresentado ali. $O$ primeiro pensamento me dizia que aquela era simplesmente uma postura defensiva e revelava o quanto os estudantes não queriam se envolver com o que tinha apresentado. Notadamente, uma postura mais confortável e menos comprometida com a pesquisa. Essa talvez fosse a constatação mais fácil de construir.

No entanto, minutos depois, passei a me questionar: tinha sido aquela cena, aquelas falas e toda aquela harmonia apressada em concordar com Estudante 1 expressão de algo compartilhado pelo grupo? Permitindo-me um momento de reflexão, apesar de já haver contornado e discordado de toda aquela situação inicial, fiquei a pensar sobre o porquê do entendimento de que aquele era mais um assunto a ser levado para a prática e não um assunto que permitisse pensar o tratamento da prática. Deixando de lado as suspeitas da razão que insistia em querer colocar em xeque o que ora descrevia e pensava de modo mais detido, constatava que, explicitamente, uma experiência em comum tinha sido vivida naquele momento!

Ao lado das concepções de experiência cultivadas no terreno individualista da modernidade, convém pensar, em consonância com a perspectiva 
estética da vida comum, o que gera comunidade, coisas que fundamentam o estar-junto. Pensar a experiência, nesse sentido, é pôr em destaque o emocional, o afeto, a sintonia criada no viver com o outro, distante da individuação moderna. É nesse sentido que é possível sustentar o esfacelamento do tom peremptório da consciência de si e abrir espaço para a consciência de grupo, espontânea, coletiva, tribal, expressão do conjunto de experiências vividas em comunidade. $O$ indivíduo se dissolve na multidão formante deixando de ser o forte produtor e dominador do mundo e da natureza e passa a integrá-lo e encená-lo, é também ator! Se, com outros a individualidade é englobada numa ambiência geral, a pessoa age e "é agida" pelo mundo. Nesse sentido, a experiência é experiência partilhada no mundo circundante, uma concepção na qual o caráter relacional e hedonista ganha força, focalizando a empatia e a intuição vivida num mesmo ambiente emocional que permite a formação em si mesma. Sobretudo, um pensamento encarnado no espaço/tempo presente, deixando de lado a lógica mecanicista e autoritária, já que não responde a sentimentos exteriores. O foco se volta para a captura da densidade e da força irreprimível do que brota e cresce junto com o outro a partir do que foi/é experimentado em comum.

Nessa perspectiva de uma experiência em comum, a atitude em desfazer aquele suposto mal-entendido sobre a pesquisa dizendo-thes que o que faríamos e compartilharíamos ao longo do semestre não tinha essa direcionalidade voltada para a sala de aula tal como foi colocado esbarrava, em alguma medida, no próprio caráter compreensivo daquela cena. No entanto, era preciso fazer tal esclarecimento. Da parte deles, estranhamento, interrogações, entusiasmos e rejeições foram alguns dos sentimentos que pareciam compor a maioria das expressões naquele momento. Um sinal da multiplicidade de experiências cotidianas que ali ocorria e, em paralelo a isso, um depoimento que, em meio às singularidades expressas, me pareceu capturar o espírito coletivo que reinava naquele dado instante. Um espírito que, de fato, traduzia a preocupação legítima, por parte dos estudantes, em ter que aplicar mais um conteúdo no ensino médio e encher a cabeça dos estudantes com todo aquele discurso sobre ciência, cotidiano, senso comum, currículo, etc. etc. No entanto, uma preocupação em si mesma já diagnóstica de experiências que, a meu ver, encontravam sentido no próprio momento do acontecimento, expressando o simbolismo formante das crenças e valores em torno dos quais o grupo, naquele dado instante, se fechava. Sentia que era o primeiro ponto final da minha história no campo 
empírico e, no entanto, outro depoimento importante surgia, sobretudo quando o assunto era tratamento/quantidade dos conteúdos, e que me convidavam a pensar no 'nós' representativo da coletividade ali reunida:

Dei aula de diferenciação entre os tipos básicos de células. [...] Durante a aula, tive que introduzir alguns conceitos de evolução para entenderem o processo de diferenciação entre os tipos de células, mesmo a professora dizendo que eles ainda não tinham visto origem da vida [...] E é isso que quero saber, a professora [referindo-se a professora regente do espaço escolar] só chamou atenção quanto a ter entrado demais em outros conteúdos para explicar evolução das células e disse que perdi muito tempo com esse conteúdo. Fico em dúvida quanto à quantidade de assunto a ser trabalhado, acho que o que apresentei de evolução foi o mínimo pra eles entenderem diferenciação celular e fui criticada por "fuga do tema" e quantidade de assunto pra uma aula. Ela disse que os alunos queriam perguntar e eu estava preocupada em terminar o conteúdo. Mas eu achava que as perguntas poderiam ser discutidas em outra aula. [...] Enfim, a quantidade sempre é um problema, desde os planos até a aula, é preciso negociar isso com a professora e com os alunos (ESTUDANTE 2, 2011 ).

Trata-se de um episódio cujas falas que retratam manifestações estéticas assumidas e identificadas no campo empírico palco de realização deste trabalho. São cenas registradas que tanto deram a pensar sobre o que foi teoricamente construído, como permitiram identificar as diferentes filiações estéticas que, naquele momento, ocupavam o mesmo espaço e, como numa dança, chocavam-se, atraiam-se e repeliam-se gerando a própria possibilidade de identificação dos totens de inter-esse naquele grupo. Apresentamos, algumas constatações no intuito de articular o pensamento estético teorizado aos cotidianos vivenciados pelo grupo e investigados neste trabalho através das ressonâncias desse pensamento expresso no episódio no tratamento dos conteúdos e, mais especificamente, no ensino de Biologia. Além disso, ilustramos a discussão com exemplos de casos vivenciados durante as observações no que se refere ao ensino dessa disciplina escolar e levantamos algumas constatações concernentes ao campo do currículo e da formação de professores.

Com base nesse episódio em particular e, no conjunto dos episódios construídos de modo geral, pudemos constatar a saturação dos modelos de 
formação de professores cuja racionalidade permanece submetendo o pensar estético e ético a uma racionalidade técnico-instrumental, o que é reforçado pelas constatações de Sousa Santos (2006). Ou seja, de um lado, é possível vislumbrar a hegemonia de concepções de currículo e formação mecânicas, centradas num pragmatismo transcendente e, por outro lado, assistir à dimensão sensível e imanente ser relegada às esferas particulares da existência, ao subjetivo do qual convém se livrar e continuar seguindo em direção a um além para o qual nada do que é vale em relação ao que advir num tempo breve ou remoto. Defendemos que a formação científica com sua forte carga de tecnicismo pode estar dando sinais de perda de evidência no espaço escolar. A forma tecnicizante de moldar os conteúdos, alijando-os dos seus contextos geo-históricos de produção que possibilitam ao aluno conferir-lhe sentido, tem perpetuado, no contexto das práticas de ensino e aprendizagem nas escolas, conforme observado na vivência dos cotidianos escolares pelo grupo, o caráter mecânico/ mnemônico do ensino e da aprendizagem pela divulgação dos produtos finais da ciência e a despreocupação quanto aos processos de produção dessa forma de conhecimento.

Nesse sentido, o conhecimento científico veiculado nas aulas de bio194 logia, conforme observado, emerge em contornos empiristas e indutivistas, perpetuando os moldes baconianos e cartesianos da ciência clássica, criando uma série de obstáculos à sua compreensão e à construção de conhecimento na sala de aula devido a seu forte caráter informativo. Emergindo desarticulado de uma moldura teórico-interpretativa, é como se a pura informação bastasse em si mesma e criasse possibilidade de construção de conhecimento na sala de aula pela simples repetição do que fora informado. É a própria estética da linguagem científica que é prejudicada pelo desejo de ressignificação curricular (CARVALHO, 2001) canalizado pelo grupo por meio da simples sumarização, "aplicação" e simplificação dos conteúdos, conforme constatado na vivência dos cotidianos e em uma das falas do episódio em análise. É Feyerabend (2007) quem reforça nosso argumento:

A educação científica tal como hoje a conhecemos tem precisamente esse objetivo. Simplifica a 'ciência' pela simplificação de seus participantes: primeiro, define-se um campo de pesquisa. Esse campo é separado do restante da história la física, por exemplo, é separada da metafísica e da teologia) e recebe uma 'lógica' própria. Um treinamento completo em tal lógica condiciona aqueles 
que trabalham nesse campo; torna suas ações mais uniformes e também congela grandes porções do processo histórico. Fatos 'estáveis' surgem e mantêm-se a despeito das vicissitudes da história. Uma parte essencial do treinamento que faz que tais fatos apareçam consiste na tentativa de inibir intuições que possam levar a que as fronteiras se tornem indistintas. [...] Sua imaginação é restringida, e até sua linguagem deixa de ser própria. Isso se reflete na natureza dos 'fatos' científicos, experienciados como independentes de opinião, crença e formação cultural (FEYERABEND, 2007, p. 34).

Concomitante a essas constatações sobre as ressonâncias dos pensamentos expressos no episódio descrito no tratamento dos conteúdos no contexto escolar, é possível construir algumas constatações no que diz respeito às discussões sobre o currículo e formação no contexto universitário. Defendemos que a formação tecno-científica tem contribuído na manutenção de conflitos estéticos, expressos na dificuldade dos licenciandos no que tange à compreensão dos discursos pedagógicos como estruturantes, anteriores à entrada na lógica do conteúdo disciplinar. Essas constatações põem em xeque a simples solução de diminuição da quantidade de conteúdos como modo de significar a educação científica nos espaços escolares. Portanto, defendemos que pode ser conveniente refletir, ao lado das supostas soluções quantitativas de adições/ subtrações mecânicas de disciplinas nas velhas e rígidas grades curriculares bem como de conteúdos nos materiais didáticos, o quanto o próprio nicho proporcionado pela ambiência nos espaços formativos pode ser determinante, em alguma medida, dos modos de estruturação das práticas de ensino daqueles que por esses ambientes enveredam. As constatações construídas nesse trabalho, em referência à formação tecno-científica, recaíram, sobretudo, nas relações forma/ conteúdo, deixando ver e convidando a pensar nas características das práticas pedagógicas investigadas entendidas como estruturantes dos modos de relação com o conhecimento em sala de aula. São relações entendidas como formadas em e formadoras de um ambiente formativo:

Fala-se da dificuldade entre a forma e conteúdo, em matéria de escrever; até se diz: o conteúdo é bom, mas a forma não etc. Mas, por Deus, o problema é que não há de um lado o conteúdo, e de outro a forma. Assim, seria fácil: seria como relatar através de uma forma o que já existisse livre, o conteúdo. Mas a luta entre a forma e o conteúdo está no próprio pensamento: o conteúdo luta por 
formar-se. Para falar a verdade, não se pode pensar num conteúdo sem sua forma. Só a intuição toca na verdade sem precisar nem de conteúdo nem de forma. A intuição é a funda reflexão inconsciente que prescinde de forma enquanto ela própria, antes de subir à tona, se trabalha. Parece-me que a forma já aparece quando o ser todo está com um conteúdo maduro, já que se quer dividir o pensar ou escrever em duas fases. A dificuldade de forma está no próprio constituir-se do conteúdo, no próprio pensar ou sentir, que não saberiam existir sem sua forma adequada e às vezes única (LISPECTOR, 1999, p. 254).

É notadamente esse existir livre que problematizamos neste texto. Para fins ilustrativos da articulação das constatações com os cotidianos escolares vivenciados pelo grupo, já que o objetivo e as discussões deste trabalho recaem num plano mais generalista, entraremos um pouco mais no território disciplinar da biologia no currículo escolar, no tratamento dos conteúdos específicos observados durante a vivência nos cotidianos investigados e tomaremos o tratamento das teorias da evolução biológica na terra como exemplo. Nesse caso específico, percebemos que a lacunarização da dimensão pedagógico-humanística e, mais especificamente, histórica na formação dos professores apresenta ressonâncias 196 claras e preocupantes no que diz respeito ao tratamento deste tema curricular. Para explicar essas constatações, recorro à filosofia da biologia desenvolvida por Mayr (2005). De acordo com ele, a biologia pode ser dividida em dois campos intrinsecamente articulados no que tange ao entendimento dos fenômenos vitais, a biologia funcional e a biologia evolutiva. No que diz respeito ao trabalho no campo da biologia evolutiva, há necessidade de construção de narrativas históricas como modo de apresentar as contingências remotas que operam em escalas distantes dos seus efeitos e que determinam a diversidade das formas viventes. Através dessa contação de história, inventa-se a trama de pressões seletivas nas quais uma determinada característica constituiu vantagem. Ou seja, a teoria da evolução biológica constitui um tema estruturante dos conteúdos de ensino na disciplina escolar de biologia, uma moldura teórica que exige o método histórico para imprimir forma aos demais conteúdos da disciplina. No entanto, a partir das observações feitas tanto nos cotidianos escolares como no universitário, constatamos que é justamente o contar uma história, o emoldurar os conteúdos, um dos obstáculos mais expressivos a serem suplantados pelos licenciandos quando na prática pedagógica em sala de aula que tem implicações diretas no tratamento mecanicista dos conteúdos no currículo. Ou seja, o 
tratamento do conhecimento biológico, nas escolas, carece de princípios organizadores e unificadores, contribuindo na manutenção do tratamento fragmentário do conhecimento dessa disciplina no espaço escolar. São obstáculos, aqui interpretados, como sendo causa e efeito do alijamento geo-histórico característico dos contornos técnicos de formação.

Essas constatações descrevem como o espaço/tempo que se ingressa ao longo do percurso formativo é estruturante de práticas de ensino, na medida em que se compartilha e expressa crenças fruto de identificações estéticas que se estabelecem com o ar que se respira nesses espaços. Ou seja, é um convite a pensar como a força da ambiência é determinante dos modos de vida em todas as suas possíveis formas de expressão, a dimensão sensível da formação, do estar-junto, do que é experimentado em comum, ao lado do que é racionalizado. Identificações espontâneas resultantes de uma espécie de interrelacionamento e ajustamentos mútuos, compartilhamento emocional e intuitivo, entre os habitantes de determinado espaço/tempo. Neste trabalho, a interpretação dessas identificações estéticas foi feita tomando a metáfora das máscaras e tendo como lócus para reflexão alguns dos espaços formativos que compõem a proposta curricular do curso de Licenciatura em Ciências Biológicas. Uma postura que compreende o nascimento de valores e princípios através do compartilhamento na relação com outrem, na participação de um acontecimento em comum. Sobretudo, uma forma de pensamento mais encarnada e enraizada que permite compreender as pessoas e a diversidade de aparências que segregam como (in)formantes de um ambiente, conferindo viscosidade e aderência às relações mundanas, das quais participam, também, os sentidos. No caso dessa investigação, as descrições interpretativas fazem aparecer filiações e adesões que permitem identificar como os praticantes da comunidade investigada expressam seus desejos de ressignificação curricular, forjados a partir do que fora vivido, revelando seus posicionamentos e permitindo o debate mais amplo sobre a pertinência deles em face dos desafios postos à educação contemporânea e, mais especificamente, ao ensino de Ciências e Biologia.

$\bigcirc$ caráter coletivo dos valores e crenças de inter-esse percebidas e descritas no grupo permitiram constatar que se tratavam de posicionamentos que, ao passo que transcendiam cada indivíduo em particular, ligava-os a uma imanência local, territorializava-os no espaço e no tempo em função do que era partilhado. Isso nos tem permitido extrapolar seu forte potencial heurístico para 
pensar a ambiência proporcionada pelas propostas curriculares na formação de professores.

Defendemos, portanto, uma concepção de formação como um processo menos moralista e menos mecânico - que, comumente, se expressa através de julgamentos indicativos fortemente exigentes e pouco construído em termos de vivência e formação, a lógica do dever ser - e mais compreensivo e orgânico - o que é tecido junto na própria existencialidade através de acontecimentos anódinos e pouco projetivos na vivência cotidiana. Ou seja, evidenciando nossa inspiração Maffesoliana (1996), defendemos uma concepção de formação vazia de sentença e cheia de formação, o que nos afasta de correntes pedagógicas marcadamente finalistas e mecânicas, marcadas por normas e obrigações e por um efeito de coerção. Notadamente, teorias pedagógicas erigidas sobre o conceito de dever ser. Em consonância com a postura fenomenológica adotada, apresentamos as constatações, criando condições de possibilidade interpretativa que dão a pensar sobre o episódio descrito e suas ressonâncias nos espaços educativos vivenciados e investigados por meio do terreno fértil que é o ambiente curricular da formação científica universitária. Tal postura, notadamente provocativa, distancia-se das sínteses direcionadoras

198 impostas externamente por sujeitos críticos, e deixa ao leitor a responsabilidade de ruminar sobre os enigmas postos neste trabalho. Apostamos na ideia de que tal postura é mais produtiva e orgânica, em termos de criação, do que o fornecimento de respostas prontas assimiladas por outros do exterior. Em outras palavras, assumimos um posicionamento notadamente nilista e finalizamos este texto fugindo de uma conclusão sinóptica cuja expressão final mais comum é o fornecimento prescritivo de soluções. Defendemos aqui uma conclusão assimétrica, imperfeita e incômoda, pois, invariavelmente, força-nos a ser responsáveis pelos nossos atos - as acusações comumente feitas de improdutividade, imobilismo e pessimismo esvaziam-se. Acreditamos que só é possível criar algo que faça sentido a cada um de nós a partir desse desequilíbrio criativo. Finalizamos essa história com essas (in)conclusões de inspiração nietzschiana mostrando-nos o sentido da intencionalidade sem direção.

\section{Notas}

1 "As grandes narrativas são, pois, histórias que as culturas contam sobre suas próprias práticas e crenças, com a finalidade de legitimá-las. Elas funcionam como uma história unificada e singular, 
cujo propósito é legitimar ou fundar uma série de práticas, uma autoimagem cultural, um discurso ou uma instituição." (PETERS, 2000, p. 18)." São, portanto, histórias de emancipação progressiva da razão e da liberdade, [...] enriquecimento da humanidade inteira através dos progressos da tecnociência capitalista e até, [...] a salvação das criaturas através da conversão das almas à narrativa cristã do amor mártir." (LYOTARD, 1992, p. 29 apud PETERS, 2000, p. 18).

2 "Evitar o pecado dos pecados - o pecado entre todos irremissível: o anacronismo" [...] "César morto por um tiro de browning"; (FEBVRE, 1942 apud BURGUIĖRE, 1993, p.47). Segundo Burguière (1993), esta fórmula de choque de Febvre ilustra a intrusão de uma época em outra que faz o anacronismo. "É mesmo bem mais grave: pois o anacronismo de instrumentos materiais não é nada diante de anacronismo de instrumentos mentais." (FEBVRE, 1942, p. 374 apud BURGUIÈRE, 1993, p. 48). "Como acentua Febvre, toda interpretação expõe ao anacronismo. [...] $\bigcirc$ anacronismo traz, em si, ao mesmo tempo, a morte e a ampliação da história; dialeticamente, o historiador tem o poder de recusar o que distorce a dimensão das coisas, o tempo, e da manipulação de um "pecado" que, bem como o pecado original, é também a fonte do conhecimento. (BURGUIÈRE, 1993, p. 48). Evitemos, portanto, a intrusão e a análise de posturas e posicionamentos assumidos na comunidade científica em outros momentos geohistóricos tendo como parâmetro categorias e teorizações contemporâneas, pois, assim, estaremos nos distanciando das histórias presentistas e arrumadinhas que caracterizam os textos anacrônicos.

3 Trabalhamos com o conceito de implicação proposto por Barbier (2007, p. 102): "Chamo implicação, hoje, o sistema de valores últimos (os que ligam à vida), manifestados em última instância, de maneira consciente ou inconsciente, por um sujeito em interação na sua relação com o mundo, e sem a qual não poderia haver comunicação".

4 De acordo com Pimentel (2009), é através de um longo período de imersão no campo de pesquisa investigado que a experiência do estranhamento em relação ao que é senso comum e que induz os padrões culturais de um modo de vida acontece. Nesse sentido, o rompimento com o senso comum, compreendido em termos do que é consenso no campo investigado, produz condição para interpretação do seu objeto de estudo à luz de teorias e sistemas de análises produzidos pelas tradições de pensamento em que a pesquisa está situada.

5 Os episódios interpretativos retratam descrições etnográficas registradas em diário de campo durante o período de observação no lócus empírico da pesquisa. Tais episódios fazem parte da pesquisa de mestrado do primeiro autor do artigo. Nesse sentido, decidimos manter, nesse momento do texto, a voz da narrativa na primeira pessoa.

6 Sigla utilizada para se referir à disciplina Evolução do Pensamento Científico, ministrada, à época, pelo professor Charbel El Hani no Instituto de Biologia da Universidade Federal da Bahia, IBIO/UFBA. A disciplina, para esta turma, não fez parte da proposta curricular do curso de Licenciatura em Biologia, sendo oferecida apenas para o Bacharelado. Assim, os licenciandos que cursaram esta disciplina a fizeram como optativa. No currículo vigente a partir de 2011.1 , foi criada a disciplina Biologia Evolutiva, obrigatória para ambas as modalidades do curso. A disciplina Evolução do Pensamento científico continua obrigatória apenas para a modalidade Bacharelado. 


\section{Referências}

ALVES, Nilda Guimarães. Cultura e cotidiano escolar. Revista Brasileira de Educação. Rio de Janeiro, n. 23, p. 62-74, maio/ago. 2003.

BARBIER, René. A pesquisa-ação. Brasília: Liberlivro, 2007.

BURGUIÈRE, André. (Org.) Dicionário das ciências históricas. Tradução Henrique de Araújo Mesquita. Rio de Janeiro: Imago, 1993.

CARVALHO, Maria Inez da Silva de Souza. Uma viagem pelos espaços educacionais do município de Santo Antônio de Jesus - possibilidades, atualizações, transituações. 2001 . 180p. Tese (Doutorado em Educação) - Programa de Pós-Graduação em Educação, Universidade Federal da Bahia, Salvador, 2001.

DIÁRIO DE CAMPO. Faculdade de Educação, Universidade Federal da Bahia, Salvador, 29 mar. 2011.

ERICKSON, Frederick. Qualitative Methods in Research on Teaching, Ocasional paper n. 81 . Michigan State University, East Lansing. Institute for Research on Teaching, 1985.

200 ESTUDANTE 1. Depoimento oral. Salvador, 29 mar. 2011.

ESTUDANTE 2. Depoimento oral. Salvador, 29 mar. 2011.

FEYERABEND, Paul. Contra o método. Tradução Cezar Augusto Mortari. São Paulo: Editora UNESP, 2007.

GLEISER, Marcelo. Criação imperfeita. 2. ed. Rio de Janeiro: Record, 2010.

LISPECTOR, Clarice. A descoberta do mundo. Rio de Janeiro: Rocco, 1999.

LOPES, Alice Casimiro. Políticas de Currículo: recontextualização e hibridismo. Currículo sem fronteiras, v. 5, n. 2, p. 50-64, jul./dez. 2005.

MAFFESOLl, Michel. No fundo das aparências. Tradução Bertha Halpern Gurovitz. Petrópolis: Vozes, 1996.

A transfiguração do político: a tribalização do mundo. Tradução Juremir Machado da Silva. 3. ed. Porto Alegre: Sulina, 2005.

O tempo das tribos: o declínio do individualismo nas sociedades pós-modernas. Tradução Maria de Lurdes Menezes. 4. ed. Rio de Janeiro: Forense Universitária, 2006. 
MAYR, Ernest. Biologia, ciência única: reflexões sobre a autonomia de uma disciplina científica. São Paulo: Companhia das Letras, 2005.

PETERS, Michael. Pós-estruturalismo e filosofia da diferença. Tradução Tomaz Tadeu da Silva. Belo Horizonte: Autêntica, 2000.

PIMENTEL, Álamo. Considerações sobre a autoridade e o rigor nas etnografias da educação. In: MACEDO, Roberto Sidnei. Um rigor outro sobre a qualidade na pesquisa qualitativa: educação e ciências humanas. Salvador: EDUFBA, 2009.

POLANYI, Michael. A lógica da Liberdade. Tradução Joubert de Oliveira Brízida. Rio de Janeiro: TopBooks, 2003.

SANTOS, Boaventura de Sousa (Org.). Conhecimento prudente para uma vida decente: um discurso sobre as ciências revisitado. 2. ed. São Paulo: Cortez, 2006.

VATTIMO, Gianni. O fim da modernidade: niilismo e hermenêutica na cultura pós-moderna. Tradução Eduardo Brandão. 2. ed. São Paulo: Martins Fontes, 2007.

Ms. Clivio Pimentel Júnior

Universidade Federal da Bahia

Faculdade de Educação

Programa de Pós-Graduação em Educação

Grupo de pesquisa Formação em Exercício de Professores | FEP | CNPQ

E-mail| clivio.pimentel@gmail.com

Profa Dra Maria Inez da Silva de Souza Carvalho

Universidade Federal da Bahia

Faculdade de Educação

Departamento de Educação \|

Programa de Pós-Graduação em Educação 
Artigo

Um sentido para as aparências: cenas e máscaras do/no cotidiano formativo

Líder do Grupo de Pesquisa Formação em Exercício de Professores | FEP |

$C N P Q$

E-mail|misc@ufba.br

Recebido 28 mar. 2014

Aceito 22 jul. 2014 